\title{
Brison-Saint-Innocent - Chemin de Pompierre 2
}

\section{Christophe Landry}

\section{OpenEdition \\ Journals}

Édition électronique

URL : http://journals.openedition.org/adlfi/15597

ISSN : 2114-0502

Éditeur

Ministère de la culture

Référence électronique

Christophe Landry, «Brison-Saint-Innocent - Chemin de Pompierre 2 », ADLFI. Archéologie de la France - Informations [En ligne], Rhône-Alpes, mis en ligne le 01 septembre 2015, consulté le 01 mai 2019.

URL : http://journals.openedition.org/adlfi/15597

Ce document a été généré automatiquement le 1 mai 2019.

(c) Ministère de la Culture et de la Communication, CNRS 


\title{
Brison-Saint-Innocent - Chemin de Pompierre 2
}

\author{
Christophe Landry
}

Code INSEE de la commune : 73059

Lien Atlas (MCC) :

http://atlas.patrimoines.culture.fr/atlas/trunk/index.php?

ap_theme=DOM_2.01.02\&ap_bbox=5.853;45.714;5.911;45.767

1 Le diagnostic mené du 10 au 12 septembre 2013 à Brison-Saint-Innocent sur une surface de $1145 \mathrm{~m}^{2}$ bordant au nord le chemin de Pompierre, a fourni l'occasion de réaliser quatre sondages sur un substrat morainique constituant le versant occidental de la montagne calcaire de Corsuet, et se trouvant $70 \mathrm{~m}$ au-dessus du niveau actuel du lac du Bourget. L'emprise sondée se trouve à $130 \mathrm{~m}$ au nord-est d'un espace funéraire antique identifié en 2007, à $225 \mathrm{~m}$ au sud-est de l'église Saint-Innocent dont la fondation pourrait remonter au premier Moyen Âge, et $100 \mathrm{~m}$ à l'est des vestiges d'un habitat peut-être contemporain, mis en évidence lors d'une précédente opération de diagnostic menée plus tôt dans l'année. Le terrain exploré cette fois se trouve une quinzaine de mètres plus haut que lesdits vestiges sur le versant, dans un secteur offrant un pendage moyen de 18,5\%, rompu par l'aménagement de petites terrasses artificielles au cours du $\mathrm{xIX}^{\mathrm{e}} \mathrm{s}$. C'est également à ce moment que le chemin de Pompierre acquiert son tracé actuel, en bordure des parcelles concernées par le présent projet de construction. L'absence de vestiges en ce point semble démontrer que les occupations anciennes du secteur se sont implantées de façon privilégiée sur les replats du versant, en aval et en amont à proximité du château. 
INDEX

Index géographique : Rhône-Alpes, Savoie (73), Brison-Saint-Innocent

operation Opération préventive de diagnostic (OPD), 2013 - n OA : 2211350

AUTEURS

CHRISTOPHE LANDRY

Inrap 